\title{
A entrevista em autoconfrontação como motor para o desenvolvimento: diálogo de uma professora com sua prática
}

Self-confrontation interviews as an engine to development: dialogue of a teacher with her practice

Flavia FAzıON

(Universidade de São Paulo)

Eliane Gouvêa LousADA

(Universidade de São Paulo)

\section{RESUMO}

O objetivo deste artigo é apresentar as análises preliminares de uma entrevista em autoconfrontação simples de uma professora de francês do estado do Paraná, que procurarão evidenciar como a situação de trabalho é percebida pela professora e como isso pode repercutir em sua atividade. Das análises do texto, pudemos observar como ela toma consciência de seu modo de agir, suas reações ao inesperado, sua postura corporal, as ações cristalizadas e repetidas, o que pode permitir uma melhor compreensão de sua atividade. É o dar-se conta de tais processos que pode proporcionar a apropriação de suas práticas e, consequentemente, seu desenvolvimento. Apresentaremos o quadro teórico no qual nos baseamos, em seguida, os procedimentos metodológicos. Passaremos para as análises parciais dos dados obtidos e, finalmente, as conclusões a que chegamos, que apontam para uma tomada de consciência de suas ações, o que, de acordo com Vigotski (2003), pode ser o motor do desenvolvimento.

Palavras-chave: autoconfrontação; tomada de consciência; desenvolvimento. 


\begin{abstract}
This article aims at presenting the preliminary analysis of a selfconfrontation interview of a French teacher from Parana state, that will show how the work situation is seen by the teacher and how it influences her activity. Analyzing the text, we could observe how she becomes aware of her way of acting, her reactions to the unexpected, her body posture, the crystalized and repetitive actions, which can help us to understand her activity. It is the fact of being aware of those processes that can allow the appropriation of her practices and therefore her development. We will present the theoretical framework that underlies the research and then the methodological procedures. Finally, we will show the partial analysis of the data and the conclusions that we found, which show the awareness process of her actions that, according to Vigotski (2003), can be the engine of development.
\end{abstract}

Key-words: self-confrontation; awareness; development.

\section{Introdução}

O trabalho do professor é uma atividade complexa, multidirecionada, que resulta dos compromissos que o conduzem a compor consigo mesmo, suas concepções e convicções profissionais, assim como com seus colegas e alunos (Espinassy e Saujat, 2003). Para apreender essa complexidade tomando por base o ponto de vista do professor, adotamos o preceito da clínica da atividade de que é fundamental que o trabalhador se torne observador de sua própria atividade, pois somente assim a experiência vivida pode tornar-se um meio de viver outras experiências (Clot, 2001). Partindo desse princípio, desenvolvemos uma pesquisa em que procuramos criar situações em que os professores pudessem verbalizar sobre sua atividade de trabalho ao assistir trechos de suas aulas filmadas tornando-se, assim, observadores de sua própria atividade. Para tanto, utilizamos um dos métodos sugeridos pela clínica da atividade, a entrevista em autoconfrontação (CLOT et al., 2000).

Nosso objetivo neste artigo, então, é apresentar as análises preliminares de uma entrevista em autoconfrontação simples de uma professora de francês do estado do Paraná, envolvida em um projeto de elaboração 
do livro didático público de francês (LDP- francês), a fim de observar como a professora observa e avalia seu agir em sala de aula. As análises procurarão evidenciar como a situação de trabalho é percebida pela professora e como isso pode repercutir em sua atividade.

Essas análises fazem parte de um conjunto maior de dados de uma pesquisa de doutorado. Tal pesquisa visa a estudar a relação do professor de francês língua estrangeira (FLE) com sua atividade, para tanto acompanhamos um projeto de elaboração do LDP organizado pela secretaria de educação do estado e desenvolvido por um grupo de cinco professores e uma coordenadora. Observamos as várias etapas desse trabalho desde seu início em 2010: as orientações oficiais que conduziram à elaboração do LDP; as etapas de elaboração, que deram origem a relatos de experiência dos professores-elaboradores; a filmagem das aulas de dois professores e as entrevistas em autoconfrontação simples e cruzada; e, finalmente, uma reunião posterior de balanço dos trabalhos, o retorno ao coletivo. Enfatizamos que, neste artigo, apresentaremos apenas a análise de um recorte dos dados, que buscará evidenciar o redobramento da atividade da professora ao ser confrontada com sua atividade. Assim, apresentaremos, em primeiro lugar, o quadro teórico no qual nos baseamos. Em seguida, os procedimentos metodológicos. Dando continuidade, passaremos para as análises parciais dos dados obtidos e, finalmente, apresentaremos as conclusões parciais a que chegamos, que apontam para uma tomada de consciência de suas ações, o que, de acordo com Vigotski (2003), pode ser o motor do desenvolvimento.

\section{Pressupostos teóricos}

Nossa pesquisa toma como base os conceitos vigotskianos sobre desenvolvimento humano e linguagem. Partindo desses conceitos base, propomos um diálogo entre os conceitos oriundos da Clínica da Atividade e da Ergonomia da Atividade dos Profissionais da Educação (ERGAPE) referentes aos métodos de (co)análise do trabalho, e o Interacionismo Sociodiscursivo (Bronckart, 1999, 2006, 2008), sobretudo os conceitos sobre o agir e análise das práticas linguageiras que se apresentam em situação de trabalho. 


\section{Vigotski - consciência e desenvolvimento}

Para Vigotski $(1925,1934)$ à luz de Bronckart (2008b), a linguagem tem um papel decisivo como determinante da hominização. Para ele, são os processos de apropriação e de interiorização dos signos mobilizados na atividade linguageira que são constitutivos das representações individuais. $\mathrm{O}$ autor sustenta que a questão do desenvolvimento deve ser vista simultaneamente em termos de continuidade e de ruptura. Ele propõe, em sua obra, duas acepções bastante diferentes - mas de maneira nenhuma contraditórias - do desenvolvimento: de um lado, o define como um processo ininterrupto de automovimento; de outro, como um processo resultante da interação conflituosa entre os recursos psicológicos disponíveis no aprendiz e os novos recursos que lhe são apresentados por seu meio cultural. Esse conflito será gerador de desenvolvimento se for "tratável" pela pessoa em seu estado atual de desenvolvimento. De acordo com o autor, eu me conheço somente na medida em que sou um outro para mim mesmo, quer dizer, na medida em que posso perceber de novo meus próprios reflexos como novos excitantes (Vigotski, 2003).

Vigotski, em seu texto "A consciência como problema da psicologia do comportamento", de 1925, propõe que, para a psicologia, o estudo somente das reações visíveis a olho nu é totalmente impotente e inconsistente, mesmo frente aos problemas mais simples do comportamento humano. No homem, o comportamento é organizado de tal forma que são justamente os movimentos internos, pouco detectáveis, que orientam e dirigem o espírito.

Ele afirma que ter consciência de suas experiências vividas não é nada além do que tê-las a sua disposição enquanto objetos (excitantes) para outras experiências vividas. A consciência é a experiência vivida de experiências vividas, exatamente da mesma maneira que as experiências vividas são simplesmente experiências vividas dos objetos. A consciência é uma interação, uma reflexão, uma excitação mútua de diferentes sistemas de reflexos (Vigotski, 2003). Assim, compreendemos que esta experiência (a consciência de si) é acessível a uma só pessoa: a que viveu a experiência. Só existo eu mesmo, e somente eu, que posso observar e perceber minhas reações secundárias, pois é somente para mim que meus reflexos servem de novos excitantes do campo proprioceptivo. 
Com base nessas proposições, Vigotski ${ }^{1}$ demonstrou que para a psicologia é necessário um método que não se baseia na percepção sensorial. Para tanto, propõe como conceito psicológico de base, o psiquismo. $\mathrm{O}$ autor compara o psiquismo a um instrumento que isola, separa, abstrai, faz escolha dos fatos da realidade. O psiquismo nunca reflete a realidade, seu papel positivo consiste justamente no fato de que "distorce subjetivamente a realidade em favor do organismo" (Friedrich, 2012). Como a relação do sujeito com o mundo é mediatizada pelo psiquismo, a percepção e o conhecimento do mundo são sempre trabalhados e o que se apresenta imediatamente ao pesquisador é apenas essa parte selecionada, parte finita da série psíquica. Para analisar um "instrumento" que funciona como filtro, não é suficiente conhecer os resultados da filtragem, ou seja, o que "sai", depois da seleção; também é preciso saber o que foi filtrado, portanto, o que não passou pelo filtro, o que foi posto de lado, o que não foi selecionado (Friedrich, 2012). Portanto, o psiquismo só pode ser definido por meio de métodos indiretos de construção de hipóteses, de reconstrução e de interpretação dos traços da filtragem.

\section{Métodos indiretos: a autoconfrontação simples e cruzada}

Tomando como ponto de partida os estudos de Vigotski apresentados acima, sobretudo as noções de instrumento, mediação e necessidade de métodos indiretos para seu estudo, Clot e Faïta (2000) propõem métodos indiretos para intervenção e transformação das situações de trabalho.

Faïta (2013), com base nos estudos de Vigotski (1925, 1934), explica que a atividade humana não pode ser isolada como um objeto, ela não se deixa apreender imediatamente. "A atividade não se toca com o dedo, não é um objeto definido" (Faïta, 2013). São necessários novos meios para estudá-la (Clot e Faïta, 2000). É necessário tomar distância para poder ver a atividade (Amigues, 2013). Assim, para transformar as situações de trabalho, a clínica e a ergonomia da atividade criaram métodos. Os procedimentos colocados em prática por esses

1. No texto "A significação histórica da crise em psicologia", de 1927, apresentado em Friedrich, 2012. 
pesquisadores propiciam a criação de um diálogo sobre a atividade de trabalho, "respeitando o princípio vigotskiano sobre a relação estreita entre interação, linguagem e desenvolvimento. Esses procedimentos são a instrução ao sósia, a autoconfrontação simples e a autoconfrontação cruzada" (Lousada, 2006). Neste trabalho, apresentaremos apenas o método da autoconfrontação (AC), pois foi o método que usamos para realizar a intervenção na situação de trabalho que estudamos.

O método da autoconfrontação foi proposto por Clot e Faïta (2000) no contexto da análise das situações de trabalho, com vistas a transformá-las. O procedimento utiliza a imagem como suporte principal das observações. Faz-se um objeto fílmico para provocar, em um novo contexto, no sujeito, a confrontação a ele mesmo e ao outro; solicita-se sua avaliação de seus próprios atos. É um processo de transformação de si, e assim chegamos a repensar nossa atividade (Faïta, 2013). É um método que visa a criar um quadro que permita o desenvolvimento da experiência profissional do indivíduo engajado em um trabalho de coanálise. As autoconfrontações - simples e cruzada - transformam o trabalho pelo deslocamento das atividades em um novo contexto, respondendo ao princípio do redobramento da experiência que caracteriza os métodos indiretos. Elas conduzem a "tomar o enunciado concreto como base material de análise das situações, dos atos e dos pensamentos humanos, o que consequentemente fornece às ciências humanas um objeto - a relação dialógica - situado na fronteira entre discurso e atividade" (Faïta e Vieira, 2003).

Amigues (2013) explica que o processo de desenvolvimento decorrente da AC advém do fato de que a controvérsia faz pensar; o indivíduo repensa sua atividade e assim podemos ter (um pouco de) acesso à atividade. É um método indireto que procura apreender a experiência profissional, por meio do redobramento da experiência. A experiência vivida passa e ser uma experiência relatada para poder tornar-se uma nova experiência.

Resumidamente, o método da autoconfrontação pode ser apresentado da seguinte forma (Clot, 2001): inicia-se um trabalho de observação das situações de trabalho junto aos trabalhadores, para a constituição do coletivo. As situações e o grupo a serem filmados são escolhidos. $\mathrm{O}$ trabalhador assiste ao vídeo de sua atividade junto com o pesqui- 
sador e comentários são tecidos sobre o filme. É a autoconfrontação simples (ACS), que por sua vez também é filmada. Em seguida pares de trabalhadores são formados e um assiste ao vídeo da atividade do outro, tecendo comentários. Por vezes controvérsias surgem sobre o estilo de ação de cada um. É a autoconfrontação cruzada, que também é filmada. Por fim, uma montagem das filmagens é apresentada ao grupo constituído inicialmente, que retoma assim o trabalho de análise - retorno ao coletivo. Um ciclo se estabelece entre o que os trabalhadores fazem, o que eles dizem do que eles fazem e, por fim, o que eles fazem do que eles dizem.

\section{Como olhar os textos produzidos}

Com base nos mesmos conceitos vigotskianos apresentados acima, o Interacionismo Sociodiscursivo (ISD) tem como questionamento central o papel que as práticas de linguagem desempenham na constituição e no desenvolvimento das capacidades epistêmicas e praxiológicas dos seres humanos. De acordo com o ISD, o agir humano não é acessível pela simples observação das condutas humanas. Ele deve ser apreendido através das interpretações, verbais, fornecidas pelos actantes.

Os textos, por sua vez, são unidades complexas compostas de vários níveis. Para ter acesso à complexidade dos textos, Bronckart $(1999,2008)$ propõe um modelo de análise que observa suas condições de produção, retomando os fundamentos de análise estabelecidos por Volochinov (1929/2010). Esse autor propõe um método de análise descendente da atividade linguageira desenvolvida que deve focalizar primeiramente as condições e os processos de interação social, uma vez que os discursos apresentam sempre um caráter dialógico.

Dessa maneira, o primeiro olhar deve ser dirigido ao contexto de produção, que é de fundamental importância para compreensão de todos os aspectos do texto. A análise do contexto de produção levanta os aspectos físicos e sociossubjetivos do momento de produção e dos sujeitos envolvidos por essa produção (enunciador e destinatário).

Tendo analisado o contexto de produção, Bronckart (2013) propõe a análise da arquitetura textual, que se divide em três níveis: 
- Infraestrutura: organização temática e organização discursiva - tipos de discurso;

- Mecanismos de textualização: conexão e coesão nominal;

- Mecanismos de responsabilização enunciativa: lugar da enunciação, vozes e pontos de vista e atribuições modais.

Além desses níveis de base, outra categoria do mesmo quadro é de extrema relevância para nossas análises. É a noção de figuras de ação, proposta inicialmente por Bronckart, Bulea e Fristalon (2004). $A$ noção de figuras de ação foi elaborada para conceitualizar formas diferentes de interpretação verbal de uma tarefa. Segundo Bulea (2010), essa noção se aplica a segmentos do texto que são efetivamente tematizados e discursivamente organizados, é o ângulo sob o qual uma pessoa recupera o cumprimento de sua tarefa no quadro geral da situação de trabalho. As seguintes categorias foram identificadas (Bulea, 2010): a figura de ação ocorrência, a figura de ação experiência, a figura de ação canônica, a figura de ação acontecimento passado e a figura de ação definição.

Tanto os níveis de análise da arquitetura textual quanto as figuras de ação serão explicados e exemplificados na análise que será apresentada a seguir.

\section{Procedimentos metodológicos}

$\mathrm{Na}$ análise do texto produzido na $\mathrm{AC}$ simples de Fátima, procuramos identificar os temas abordados durante a entrevista. Identificamos seis grandes temas:

- Funcionamento do curso: horário, atraso dos alunos, evasão, cópias

- Observação da professora sobre seu comportamento/postura em sala de aula (observação de si)

- Atividades da/na aula - hábitos

- Os alunos

- As ferramentas: o quadro negro, o manual didático

- Organização da sala 
Tais temas foram introduzidos ora pela pesquisadora, ora pela professora, e dentre os temas observados, escolhemos para analisar e comentar neste artigo o de maior recorrência: "Observação da professora sobre seu comportamento/postura em sala de aula (observação de si)". A retomada do tema pela professora ao longo de toda a entrevista nos remete à proposição de Vigotski de que "ter consciência de suas experiências vividas é tê-las à sua disposição como objeto para outras experiências vividas. A consciência é a experiência vivida de experiências vividas" (Vigotski, 2003) ${ }^{2}$. Assim, veremos, no decorrer dessas análises, como a professora parte das imagens do vídeo como ponto de partida para tomar consciência de sua atividade.

Nossas análises seguiram o modelo de análise proposto pelo ISD (Bronckart 1999, 2008, 2013). Nos excertos aqui selecionados, apresentaremos as análises do contexto de produção, infraestrutura geral do texto (organização temática e organização discursiva - tipos de discurso), mecanismos de responsabilização enunciativa e figuras de ação.

\section{Análise parcial da autoconfrontação simples de Fátima}

A filmagem da autoconfrontação simples de Fátima foi realizada em sua casa, alguns meses após a filmagem da aula (filmagem 02/05/12 e ACS 18/09/12).

No dia da autoconfrontação, a pesquisadora explicou à professora que ela poderia parar o vídeo em qualquer momento para fazer seus comentários, assim como o faria a pesquisadora. A língua escolhida foi o francês, uma vez que o grupo de professores de francês do qual as duas fazem parte tem por hábito utilizar essa língua sempre que se reúne, em diversas situações.

Seguindo as orientações de Clot (2001), a professora recebeu o vídeo da aula e lhe foi solicitado que assistisse e selecionasse os trechos sobre os quais gostaria de comentar na ACS. A pesquisadora também selecionou trechos da aula filmada sobre os quais gostaria de suscitar os comentários da professora. De acordo com o autor, é importante 
salientar trechos que causem estranhamento ou possam provocar controvérsias entre os trabalhadores.

\section{Procedimentos de análise}

De acordo com Bronckart (1999), o contexto de produção pode ser definido como o conjunto dos parâmetros que podem exercer uma influência sobre a forma como um texto é organizado. Esses fatores estão agrupados em dois planos: o do mundo físico e o dos mundos social e subjetivo.

No primeiro plano, todo texto resulta de um ato realizado em um contexto físico, definido por quatro parâmetros:

- o lugar de produção

- o momento de produção

- o emissor

- o receptor

No segundo plano, o contexto sociossubjetivo no qual se inscreve a interação comunicativa implica as relações de norma, valores, regras (mundo social) e a imagem que o agente dá de si ao agir (mundo subjetivo), e pode também ser decomposto em quatro parâmetros:

- o lugar social de produção

- a posição social do emissor

- a posição social do receptor

- o objetivo da interação

Analisando o contexto de produção do texto produzido na entrevista em relação a seu contexto físico, a autoconfrontação de Fátima ocorreu em uma terça feira à tarde, período de folga da professora. Ela optou por fazermos a autoconfrontação em sua casa, assim não tivemos nenhuma interferência durante o procedimento. $\mathrm{O}$ equipamento de gravação utilizado foi a filmadora Sony digital DCR-DVD508. Fátima mostrou-se bastante ativa durante o procedimento, fazendo muitas pausas em diversos trechos. 
Em relação a seu contexto sociossubjetivo, é importante analisá-lo tanto do ponto de vista da pesquisadora quanto da professora. A pesquisadora é alguém que desempenha as mesmas funções que Fátima no CELEM, vendo-a como sua colega de trabalho e com uma formação próxima da sua, com quem pode trocar experiências. O seu principal objetivo na interação era coletar dados para a tese, mas, após observar a aula, interessava-lhe também discutir alguns problemas semelhantes aos que enfrenta em sala. Provavelmente em razão da relação de proximidade e por serem colegas hierarquicamente do mesmo nível, a pesquisadora sentiu certo constrangimento em questionar a professora sobre sua conduta em sala de aula, restringindo suas questões a problemas que envolvem as dificuldades em relação ao funcionamento do curso, organização da sala e atrasos dos alunos, fato que discutiremos adiante.

Do ponto de vista da professora, além da intenção de ajudar a pesquisadora, podemos perceber seu interesse em comentar detalhes de sua atividade, principalmente no que tange suas decisões e atitudes face aos acontecimentos da aula (pergunta dos alunos, postura corporal, alunos atrasados).

Com relação organização temática, como dissemos anteriormente, selecionamos o tema observação da professora sobre seu comportamento/postura em sala de aula (observação de si). Durante a interação, observamos que há um equilíbrio na distribuição dos turnos, e que a pesquisadora questiona poucas vezes a professora, sobretudo para que explore a aprofunde o que acaba de comentar, porém sem a intenção de criar controvérsias, como procuramos demonstrar na análise do contexto. Seus turnos são curtos e muitas vezes concordam com o que Fátima comenta ou explica. A professora, por sua vez, tem alguns turnos mais longos, pois procura explorar, na busca de uma explicação, as situações que se desenrolam na aula.

Partindo para a análise da organização discursiva e das marcas linguísticas, observamos a mobilização predominante do discurso interativo, discurso característico dos diálogos, com um segmento de relato interativo, no qual a professora conta o que ocorreu em algum determinado momento independentemente da imagem do vídeo. Abaixo mostramos um exemplo de discurso interativo: 
Fat (138) - moi... je sais que j'ai déjà remarqué... je fais beaucoup de gestes... je parle avec les mains... j'ai bien remarqué ça ((risos))

Pesq (139) - tu parles toujours en français... tu parles pas en portugais

Fat (140) - parfois je mélange, mais ::

Pesq (141) - pas trop... hein?

Fat (142) - mais là... cette classe... je crois que j'ai parlé entièrement en français

No discurso interativo temos a presença dos agentes da interação, através dos dêiticos je, moi e $t u$. O tempo predominante é o presente, com presença do pretérito perfeito que marca a anterioridade em relação a esse presente. Temos aqui o mundo discursivo da aula (vídeo) reconstituído como se concomitante ao mundo da interação professora - pesquisadora. A predominância do discurso interativo nesses excertos nos aponta a tomada de consciência de Fátima sobre sua atividade, uma vez que no momento da aula, as ações são vividas, porém não percebidas conscientemente. É no momento da ACS que ela tem a possibilidade de reviver a situação e falar sobre isso.

No que tange à responsabilização enunciativa, buscamos identificar as marcas linguísticas da situação da ação de linguagem que se concretizam no texto (o lugar da enunciação), a fim de compreender como os protagonistas estão nele representados. Buscamos também identificar as diferentes vozes que aparecem no texto e as modalizações que permitem aos enunciadores exprimirem seu posicionamento.

Observando os dêiticos de pessoa, uma vez que a ACS se caracteriza pela relação dialógica entre a professora e a pesquisadora na situação de ação de linguagem presente, as duas ocupam ora posição de enunciador, ora de destinatário, representadas pela alternância dos dêiticos pessoais je, $m o i$, $t u$ :

Fat (356) - mais je suis étonnée ahn... comment je fais... je fais beaucoup de gestes...

Pesq (357) - ça t'étonne de voir...de te voir faire ça?

Fat (358) - oui

Pesq (359) - mais ça t'étonne tu trouves que c'est bien ou pas? 
Fat (360) - non... c'est bien... c'est bien... on ne se rend pas compte oui

Porém, em alguns segmentos, encontramos os dêiticos je e moi representando a professora na situação de aula. Lousada (2006) explica que podemos, então, observar dois planos enunciativos: o plano da interação em curso, entre professora e pesquisadora, e o plano enunciativo da reprodução da aula.

Fat (180) - je ne suis pas contente...

Pesq (181) - pas contente?

Fat (182) - oui... parce que la fille est en retard...

Pesq (183) - en plus elle fait beaucoup de bruit... hein?

Fat (184) - oui... donc... ça me stresse un peu et ça dérange la dynamique

O dêitico on ocupa também um lugar importante no texto. No trecho abaixo tem o valor de a gente, num sentido amplo, que pode englobar a professora, a pesquisadora e todos os colegas professores:

Fat (356) - mais je suis étonnée ahn... comment je fais... je fais beaucoup de gestes..

Pesq (357) - ça t'étonne de voir...de te voir faire ça?

Fat (358) - oui

Pesq (359) - mais ça t'étonne tu trouves que c'est bien ou pas?

Fat (360) - non... c'est bien... c'est bien... on ne se rend pas compte oui

Pesq (361) - uhum... uhum... on fait pas mal des choses qu'on se rend pas compte... n'est-ce pas? c'est quand on se voit faire

Outra ocorrência importante é a utilização de pronomes pessoais de terceira pessoa ( $i l$, elle, ils) e unidades lexicais que designam os alunos (les élèves). Apesar de representarem o que está fora da situação de ação de linguagem, essas unidades são importantes por marcarem o fato de estarem intimamente ligados às ações da professora em aula. Vejamos os exemplos abaixo: 
Fat (55) - là... je crois que je... je ne sais pas comment expliquer... parce que même à la fac les profs n'ont pas expliqué comment on va utiliser le trait-d'union... c'est avec le temps... quand on écrit... on fait des choses mais je... sais pas vraiment la règle... quand on utilisait le trait-d'union... et là...je j'étais un peu stressée... hein ((risos))

Pesq (56) - ah... oui... angoissée...

Fat (57) - oui... avec cette question parce que pourquoi le traitd'union...mais c'est avec le temps...

Pesq (58) - qu'on maîtrise...

Fat (59) - qu'on maîtrise les choses mais... parfois les élèves nous posent des questions un peu ((risos)) biza::rres

Nesse trecho, Fátima generaliza para les élèves a situação de ter se sentido estressada com a questão posta por um aluno. Isso nos faz pensar que a mesma situação pode ter ocorrido outras vezes, em outras aulas, porém por meio da ACS ela pôde falar sobre o assunto com a pesquisadora, após ter refletido sobre ele sozinha, quando da sua visualização do vídeo da aula antes da entrevista.

No excerto abaixo, observamos a utilização de ils e eux, relatando um fato ocorrido na aula:

Pesq (251) - tu reprends toujours comme ça... une première fois tout le monde ensemble?

Fat (252) - oui... oui... mais ce/ c'est vrai que la phrase... elle est très longue et ils ne sont pas habitués... hein... moi je suis déjà habituée donc je parle vite...

Pesq (253) - oui

Fat (254) - eux... non... eux non... donc... c'était difficile... après... la catastrophe

Pesq (255) - pourquoi la catastrophe?

Fat (256) - Parce qu'ils commencent bonjou .......

Pesq (257) - ils se perdent?

Fat (258) - ils se perdent... parfois il faut parler ahn... doucement... pour qu'ils puissent accompagner

Nesse trecho, a professora relata que a maneira como conduziu a atividade não atingiu o objetivo que desejava. A possibilidade de 
assistir a aula lhe permitiu repensar o modo de agir durante esse tipo de atividade, a fim de que possa buscar alternativas de como lidar com situações equivalentes para que os alunos possam ter um melhor aproveitamento.

O estudo da implicação enunciativa nos mostra a presença dos alunos permeando a atividade da professora, consequentemente seu discurso. Observamos também a presentificação das situações do vídeo, pelo fato de a professora estar se valendo das experiências vividas como objeto para uma nova atividade, a de observar e analisar sua atividade, suas ações e reações em aula, vivendo assim uma nova experiência.

Passaremos, agora, ao estudo das vozes que se manifestam nos textos. De acordo com Bronckart (1999), "as vozes podem ser definidas como as entidades que assumem (ou às quais são atribuídas) a responsabilidade do que é enunciado".

Além da voz do professor e da pesquisadora, observamos também as vozes da didática, do senso comum e da fala egocêntrica reconstituída (Dantas Longhi, 2013). A voz da professora é predominante nos excertos analisados, uma vez que, conforme expusemos anteriormente, o tema analisado é "observação da professora sobre seu comportamento/ postura em sala de aula (observação de si)". Porém, nos trechos em que podemos observar as dúvidas de Fátima quanto a seu agir, ela se apoia na voz do senso comum, como podemos ver abaixo:

Fat (55) - là... je crois que je... je ne sais pas comment expliquer.. parce que même à la fac les profs n'ont pas expliqué comment on va utiliser le trait-d'union... c'est avec le temps... quand on écrit... on fait des choses mais je... sais pas vraiment la règle... quand on utilisait le trait-d'union... et là...je j'étais un peu stressée... hein ((risos))

Pesq (56) - ah... oui... angoissée...

Fat (57) - oui... avec cette question parce que pourquoi le traitd'union...mais c'est avec le temps...

Nesse trecho, a professora transfere a responsabilidade da enunciação a on com valor indefinido, e ao fato de que o aprendizado se dá com o tempo, com o uso, e que não há regras que expliquem todas as coisas. 
Já nos trechos nos quais ela explica como desenvolve as atividades direcionadas aos alunos, percebemos a voz da didática como apoio a suas ações:

Pesq (83) - tu fais souvent ça?

Fat (84) - souvent... souvent

Pesq (85) - demander sur le week-end... des choses comme ça?

Fat (86) - oui ((risos)) parfois... je délire un peu... ((risos)) mais c'est toujours comme ça... je pose des questions... il faut qu'ils parlent

Fat (399) - je ne donne pas que le verbe... hein... j'ajoute toujours quelque chose pour qu'ils puissent associer

Pesq (400) - tu fais une petite phrase là avec les verbes

Fat (401) - uhum

A voz da fala egocêntrica reconstituída, tal como apresentada por Dantas-Longhi (2013), representa a tentativa do professor de recriar para os pares as reflexões que se passaram por sua mente no momento da atividade. Trata-se de uma fala que é reproduzida em voz alta e tem estrutura dialogal, como uma conversa do sujeito consigo mesmo. $\mathrm{Na}$ ACS de Fátima, vemos essa voz aparecer no trecho abaixo:

Fat (276) - footing... donc... je me suis dit... je dis une bêtise ((risos))... footing... parce que j'ai entendu parler déjà

No que se refere às modalizações, encontramos principalmente exemplos de modalizações lógicas. Essas modalizações apresentam os elementos de seu conteúdo do ponto de vista de suas condições de verdade, como fatos atestados, possíveis, prováveis, necessários (Bronckart, 1999). Nos trechos analisados, a opinião da professora é expressa por meio da utilização dos verbos croire e savoir (acreditar e saber). O verbo savoir aparece sempre na forma negativa, expressando as dúvidas de Fátima sobre sua atitude durante a aula:

Fat (88) - heu... je sais pas si parfois je ...j'exagère... si je pose beaucoup de questions là... parfois il faut trouver l'équilibre... être discrète

Fat (404) - là... je j'ai un trou de mémoire... je savais pas si on pourrait dire «je fais un gâteau» ou «je prépare un gâteau» 
Já as modalizações lógicas com o verbo croire exprimem uma atestação de verdade, passagens nas quais Fátima concorda com a situação de aula em questão:

Fat (142) - Mais là, cette classe, je crois que j'ai parlé entièrement en français.

Fat (169) - je crois que fait partie de ma personnalité ahn... je suis comme ça et... c'est pas que je suis quelqu'un de rrrr... non mais... je suis sérieuse

Nas modalizações deônticas encontradas, a professora dirige o dever a si mesma, a partir de sua observação do decorrer da aula, como uma regulação para as próximas vezes que for desenvolver atividades similares:

Fat (88) - heu... je sais pas si parfois je ...j'exagère... si je pose beaucoup de questions là... parfois il faut trouver l'équilibre... être discrète

Pesq (89) - tu penses que c'est trop?

Fat (90) - hum...il faut... un peu moins

Fat (258) - ils se perdent... parfois il faut parler ahn... doucement... pour qu'ils puissent accompagner

Encontramos ainda uma ocorrência de modalização apreciativa, na qual Fátima avalia positivamente sua postura, ao se dar conta de como gesticula em aula:

Fat (356) - mais je suis étonnée ahn... comment je fais je fais beaucoup de gestes..

Pesq (357) - ça t'étonne de voir...de te voir faire ça?

Fat (358) - oui

Pesq (359) - mais ça t'étonne tu trouves que c'est bien ou pas?

Fat (360) - non... c'est biEN... c'est bien... on ne se rend pas compte oui

De acordo com Bulea (2010:123), os textos produzidos nas entrevistas caracterizam-se tanto por uma alternância temática quanto pela 
alternância de tipos de discurso. Assim, as entrevistas caracterizam-se por uma dupla heterogeneidade, temática e discursiva. É em relação à gestão conjunta e situada desses dois planos da atividade linguageira que se elaboram as figuras interpretativas do agir chamadas figuras de ação. Esses dois planos de atividade linguageira citados por Bulea (2010) dialogam diretamente com a questão apresentada por Lousada (2006) sobre a alternância de dois planos enunciativos presentes nas entrevistas de autoconfrontação. Lousada (2006) explica que imbricados na entrevista estão o plano da interação em curso e o plano enunciativo da reprodução da aula, e que é no confronto entre esses planos que temos o plano do comentário que permite a tomada de consciência sobre a experiência vivida na aula. Vemos aqui a complexa alternância tanto no plano enunciativo quanto no plano das atividades linguageiras que se constroem nos textos produzidos nas entrevistas em autoconfrontação.

Com relação às figuras de ação, segundo Bulea (2010), a figura de ação ocorrência caracteriza-se por um forte grau de contextualização, e o agir está espaço-temporalmente acessível e numa relação de muita proximidade com a situação da entrevista, sendo, assim, composta basicamente pelo discurso interativo. Visto que a AC se desenrola diante do vídeo da aula da professora, os participantes se referem às imagens constantemente, e a agentividade é marcada pelo pronome $\mathrm{eu}$. A figura de ação ocorrência é a mais recorrente na autoconfrontação de Fátima. Nos trechos abaixo vemos alguns exemplos:

Fat (180) - je ne suis pas contente...

Pesq (181) - pas contente?

Fat (182) - oui... parce que la fille est en retard...

Pesq (183) - en plus elle fait beaucoup de bruit... hein?

Fat (184) - oui... donc... ça me stresse un peu et ça dérange la dynamique

Pesq (251) - tu reprends toujours comme ça... une première fois tout le monde ensemble?

Fat (252) - oui... oui... mais ce/ c'est vrai que la phrase... elle est très longue et ils ne sont pas habitués... hein... moi je suis déjà habituée donc je parle vite... 
Fat (254) - eux... non... eux non... donc... c'était difficile... après... la catastrophe

A figura de ação experiência, por sua vez, representa um agir sob o ângulo da cristalização pessoal de múltiplas experiências vividas do agir, que é apresentado de modo descontextualizado, geralmente no presente, marcado por advérbios de valor generalizante e reiterativo (sempre, normalmente etc.).

Fat (86) - oui ((risos)) parfois... je délire un peu... ((risos)) mais c'est toujours comme ça... je pose des questions... il faut qu'ils parlent

Fat (92) - mais ça va... je fais toujours comme ça... toujours attentive... mais pas dépasser.. le bord

Fat (354) - donc je... circule là... je jette un coup d'oeil pour ahn voir si ça marche... s'il y a des problèmes... donc... un petit tour...

Fat (399) - je ne donne pas que le verbe... hein... j'ajoute toujours quelque chose pour qu'ils puissent associer

Pesq (400) - tu fais une petite phrase là avec les verbes

Fat (401) - uhum

Através dessa análise, por meio da figura de ação ocorrência, observamos como Fátima busca explicar-se ao se ver confrontada aos dilemas de sala de aula, o que pode contribuir para a abertura de novas saídas nas situações difíceis. Já a figura de ação experiência mostra uma situação consolidada, uma repetição do agir avaliada positivamente pela professora, como influência do bom andamento da aula. Esse fato é interessante se comparado aos resultados encontrados por Dantas-Longhi (2013) sobre as figuras de ação experiência. No estudo da pesquisadora, com professores iniciantes, a figura de ação experiência aparece de forma negativa, na qual os professores expressam seu descontentamento com o que fizeram, como fizeram. Ao contrário deles, Fátima é uma professora experiente, que já apresenta práticas consolidadas e validadas por sua experiência.

Ao analisarmos o modo como Fátima observa seu agir em aula, podemos inferir possíveis transformações das possibilidades e dos impedimentos das ações. Ao recuperar o que escapa, o que está para além do observável, a professora traz à luz o que não pôde ser realizado 
em algum momento, ou o que fez e não atingiu seu objetivo, ou ainda as reações face às situações inesperadas. Para a clínica da atividade, é o que se chama de real da atividade (Clot, 2001). É essa tomada de consciência, como explica Vigotski (2003), que pode permitir à Fátima compreender a diversidade de suas práticas e, consequentemente, ser fonte de desenvolvimento.

\section{Considerações finais}

Neste artigo, procuramos compreender como, a partir das análises de uma autoconfrontação simples, uma professora de francês do estado do Paraná, observa e avalia seu agir em sala de aula. Para alcançar esse objetivo, analisamos trechos da entrevista em autoconfrontação simples selecionados com base no conteúdo temático observação da professora sobre seu comportamento/postura em sala de aula (observação de si). Esse tema foi o escolhido por ser o mais recorrente na entrevista, o que indica o estranhamento da professora perante seu próprio agir.

Das análises do texto, pudemos observar como Fátima toma consciência de seu modo de agir, suas reações ao inesperado, sua postura corporal, as ações cristalizadas e repetidas, o que pode permitir uma melhor compreensão de sua atividade. É o dar-se conta de tais processos que pode proporcionar a apropriação de suas práticas e, consequentemente, seu desenvolvimento.

Como expusemos anteriormente, essas análises são o recorte de uma pesquisa maior, que compreende outros professores e outros conjuntos de dados. Os resultados aqui apresentados, juntamente com as outras análises, nos auxiliarão a interpretar os dados da pesquisa. Esses resultados serão discutidos com os participantes em reuniões de retorno ao coletivo, possibilitando a todos os envolvidos, professores e pesquisadora, aprimorar o conhecimento sobre seu métier.

Ao fazer circular os pontos de vista dos professores sobre seu trabalho, seus conflitos, as reações aos acontecimentos imprevisíveis da sala de aula, as saídas encontradas e estimadas positivas, as atividades que não deram certo, os professores são levados a refletir sobre outros modos de realizar a mesma tarefa, o que pode resultar em uma ampliação do “poder de agir" dos professores (Clot, 2008) 
e possivelmente em uma transformação do trabalho. A realização da atividade assim revisitada pode influenciar um coletivo maior na medida em que essas experiências serão discutidas em outras reuniões escolares, com outros professores, bem como nos encontros de formação continuada realizados anualmente entre os professores de línguas do estado do Paraná.

Recebido em julho de 2013

Aprovado em abril de 2015

E-mails:

elianelousada@uol.com.br

flaviafazion@gmail.com

\section{Referências Bibliográficas}

Amigues, René. 2013. Analyse du travail pour la formation : quelques repères et questions. Aula proferida no curso «Analisar o trabalho educacional: uma abordagem a serviço do métier", 21 a 26 de novembro de 2013, FFLCH - USP, São Paulo.

BronCKART, Jean-Paul. 1999. Atividades de linguagem, textos e discursos: Por um Interacionismo Sociodiscursivo. $2^{\circ} \mathrm{ed}$. São Paulo: EDUC.

2006. Atividades de Linguagem, Discurso e Desenvolvimento

Humano. Campinas, SP: Mercado das Letras. (Coleção ideias sobre linguagem).

. 2008. O Agir nos Discursos: das concepções teóricas às concepções dos trabalhadores. Campinas, SP: Mercado das Letras (Coleção ideias sobre linguagem).

. 2008b. Un retour nécessaire sur la question du développement.

In: Vygotski et les recherches en éducation et en didactiques des disciplines. Presses Universitaires de Bordeaux.

2013. Évolutions recentes de la conception et du statut des genres textuels dans la perspective de l'ISD. Conferência proferida no VII SIGET, 03 a 06 de setembro, Fortaleza, Ceará.

BroncKart, Jean-Paul; Bulea, Ecaterina; Fristalon, Isabelle. 2004. Les conditions d'émergence de l'action dans le langage. Cahiers de Linguistique Française, 26.

Bulea, Ecaterina. 2010. Linguagem e efeitos desenvolvimentais da interpretação da atividade. São Paulo: Mercado de Letras. 
Clot, Yves. 2008. Travail et pouvoir d'agir. Paris: PUF.

Cцот, Yves; Faïta, Daniel. 2000. Genre et style en analyse du travail, concepts et méthodes. In: Travailler, Revue internationale de Psychopathologie et Psychodynamique du Travail, n.4.

Clot, Yves; Prot, Bernard; Werthe, Christiane. 2001. Clinique de l'activité et pouvoir d'agir. Éducation permanente $\mathrm{n}^{\circ} 146$.

Dantas-LonghI, Simone Maria. 2013. Como os jogos podem revelar outras dimensões do trabalho do professor de língua estrangeira? Dissertação (Mestrado em Estudos Linguísticos, Literários e Tradutológicos em Francês) - Universidade de São Paulo, São Paulo.

Espinassy, Laurence; SAUJAT, Frédéric. 2003. Enseigner les arts plastiques en ZEP: les dessous du métier. Recherche et formation, INRP, n.44.

FAÏTA, Daniel. 2013. L'analyser du travail. Aula proferida no curso "Analisar o trabalho educacional: uma abordagem a serviço do métier", 21 a 26 de novembro, FFLCH - USP, São Paulo.

FaïtA, Daniel; VieIRA, Marcos. 2003. Réflexions méthodologiques sur l'autoconfrontation croisée. Skholê, hors-série 1.

Friedrich, Janette. 2012. Lev Vigotski: mediação, aprendizagem e desenvolvimento: uma leitura filosófica e epistemológica. Campinas, SP: Mercado de letras.

LousADA, Eliane Gouvêa. 2006. Entre o trabalho prescrito e o realizado: um espaço para a emergência do trabalho real do professor. Tese (Doutorado em Linguística Aplicada e Estudos da Linguagem) Pontifícia Universidade Católica de São Paulo, São Paulo.

Vigotski, Lev S. 2003. La conscience comme problème de la psychologie du comportement [1925]. In: Conscience, inconscient, émotions. Paris: La Dispute. 2003. Conscience, inconscient, émotions. Paris: La Dispute. 1997. Pensée et langage[1934]. Paris: La Dispute.

Volochinov, Valentin N. 2010. Marxismo e filosofia da linguagem [1929]. São Paulo: Hucitec. 